\title{
Comparative analysis of feeding techniques for cylindrical surrounding patch antenna
}

\author{
Erhiega N. Umayah, Viranjay M. Srivastava \\ Department of Electronic Engineering, Howard College, University of KwaZulu-Natal, South Africa
}

\begin{tabular}{l}
\hline \hline Article Info \\
\hline Article history: \\
Received Mar 15, 2019 \\
Revised Mar 9, 2020 \\
Accepted Apr 11, 2020 \\
\hline
\end{tabular}

\section{Keywords:}

Antenna

Inset-feed

Polyimide

Radiation pattern

Return loss

\begin{abstract}
In this research work, a cylindrical surrounding patch antenna (CSPA) with improved performance parameters based on inset feed method compared to other feed techniques has been proposed for $1.8 \mathrm{GHz}$ applications. The designed and simulated CSPA is a rotary version of an initially designed rectangular planar patch antenna (RPPA). The RPPA is mounted on a cylindrical surface with radius (r) $10 \mathrm{~mm}$ which is an increased curvature for better -10 dB S-parameter $\left(S_{11}\right)$, impedance band width $(B W)$, voltage standing wave ratio (VSWR), radiation pattern, and gain. The copper radiating patch has been conformed on the surface of the grounded flexible polyimide substrate with relative permittivity $\left(\varepsilon_{\mathrm{r}}\right) 3.5$ and thickness (h) $1.6 \mathrm{~mm}$ at normalized input impedance of $50 \Omega$. Results for the RPPA and the proposed CSPA have been compared with existing designs in terms of antenna size, resonant frequency $\left(\mathrm{f}_{\mathrm{r}}\right)$, return loss $\left(\mathrm{S}_{11}\right)$, and gain while taking cognizance of the feeding techniques. The $\mathrm{S}_{11}, \mathrm{BW}, \mathrm{VSWR}$, and gain are-12.784 dB, $28 \mathrm{MHz}, 1.8$, and $4.81 \mathrm{dBi}$ respectively for the rectangular planar patch antenna and $-35.571 \mathrm{~dB}, 66 \mathrm{MHz}, 1.5$, and $3.74 \mathrm{dBi}$, respectively for the cylindrical surrounding patch antenna.
\end{abstract}

Copyright $\odot 2020$ Institute of Advanced Engineering and Science. All rights reserved.

\section{Corresponding Author:}

Erhiega N. Umayah,

Department of Electronic Engineering, Howard College,

University of KwaZulu-Natal,

Durban-4041, South Africa.

Email: erhiega @ieee.org

\section{INTRODUCTION}

High performance flexible conformal patch antenna is the main focus of research and applications for point-to-point communications, radar, medical industries, and aerospace [1,2]. This is because it possesses better performance parameters like high gain, low return loss, higher bandwidth etc. compared to its planar counterpart. Planar patch antennas are known for their versatility in non-planar geometries and are thus applicable in different situations, construction, and suitability for integration with microwave circuits.

The radiating patch (element) is of various structures (configuration) with the most common been rectangular or circular in shape [3-5]. However, the planar and conformal patch antennas have some similar characteristics such as low profile, simplicity, lightweight, ease of integration with microwave-integrated systems. Cylindrical surrounding patch antennas (CSPA) is preferred because of its additional advantages. This include reduction of aerodynamic drag, mechanical robustness on host surfaces, reduced radar cross-section, wider angular coverage and ease of concealing within host surface making it an integral part of the host $[1,6,7]$. Reported research based on conformal patch antennas have demonstrated that the performance parameters of antennas are affected by feeding technique/method [8-12]

This present research work has analyzed the design and simulation of inset feed cylindrical surrounding patch antenna obtained from a conformal rectangule shaped planar-patch antenna at $1.8 \mathrm{GHz}$ frequency band for mobile communication and automotive applications where antennas have to be integrated 
on curved surfaces. The approach takes into account the effect of curvature radius ( $\mathrm{r}$ ) on return loss $\left(\mathrm{S}_{1,1}\right)$, impedance Band Width (BW), Voltage Standing Wave Ratio, and the E- and H- plane radiation patterns of the antennas [11-15]. This research work has resolved the limitations of coaxial, probe and proximity feeding techniques and has justified that microstrip inset-feed technique can mitigate the shortcomings of other feeding methods.

This paper has been organized as follows: Section 2 deals with the design and modelling of the CSPA detailing the physical dimensions of the RPPA and the model of the proposed inset feed CSPA. Section 3 deals with results and discussions and its comparison with other existing model has been performed in section 4. Finally, section 5 presents the conclusion of the work and recommends future aspect.

\section{PROPOSED MODEL OF THE CYLINDRICAL SURROUNDING PATCH ANTENNA}

The designing of the cylindrical surrounding patch antenna has been first derived from a fundamental design of a rectangular patch and further optimized and conformed on the cylindrical surface. Subsequent subsections present the ordered design details.

\subsection{Physical dimensions of rectangular planar patch antenna}

The optimized physical dimension details of the designed rectangular planar patch antenna as shown in Figure 1 has been calculated by transmission line method by the use of (1) to (5). Table 1 depicts the complete details of the physical dimensions of the rectangular planar patch antenna [14-16].

The width of the patch $\left(\mathrm{w}_{\mathrm{p}}\right)$ is:

$$
w_{p}=\frac{c}{2 f_{r} \sqrt{\frac{\left(\varepsilon_{r}+1\right)}{2}}}
$$

where $\mathrm{c}, \mathrm{f}_{\mathrm{r}}$ and $\varepsilon_{\mathrm{r}}$ are the velocity of light, resonant frequency, and permittivity of the substrate respectively. The width of the ground plane $\left(\mathrm{w}_{g}\right)$ which is the same as that of the substrate $\left(\mathrm{w}_{\mathrm{s}}\right)$ is given as:

$$
w_{g}=w_{s}=6 h+w_{p}
$$

Also, the length of the ground plane $\left(l_{\mathrm{g}}\right)$ which is the same as that of the substrate $\left(1_{\mathrm{s}}\right)$ is obtained from:

$$
l_{\mathrm{g}}=6 h+l_{p}
$$

However, the resonant frequency $\left(\mathrm{f}_{\mathrm{r}}\right)$ is:

$$
f_{r}=\frac{c}{2 l_{e f f} \sqrt{\varepsilon_{r}}}
$$

and finally, the effective length of the patch $\left(l_{\mathrm{eff}}\right)$ is given by:

$$
l_{\text {eff }}=l_{p}+2 \Delta l_{p}
$$

where the extended length $(\Delta \mathrm{l})$ due to fringing effect is:

$$
\frac{\Delta l_{p}}{h}=0.412\left(\frac{\left(\varepsilon_{\text {reff }}+0.3\right)\left(w_{p} / h+0.264\right)}{\left(\varepsilon_{\text {reff }}-0.258\right)\left(w_{p} / h+0.8\right)}\right)
$$

Moreover, the effective dielectric constant $\left(\varepsilon_{\text {reff }}\right)$ due to dielectric constant of the substrate $\left(\varepsilon_{\mathrm{r}}\right)$ and that of air $\left(\varepsilon_{\mathrm{o}}\right)$ which is responsible for fringing field (effect) is given as:

$$
\varepsilon_{r e f f}=\frac{\varepsilon_{r}+1}{2}+\frac{\varepsilon_{r}-1}{2}\left(1+\left(\frac{12 h}{w_{p}}\right)\right)^{-1 / 2}
$$




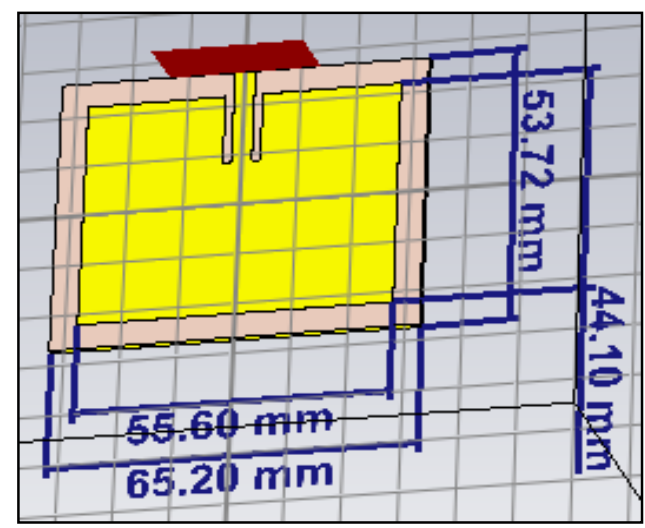

Figure 1. Dimension details of the designed rectangular planar patch antenna

Table 1. Physical parameters of the rectangular planar patch antenna

\begin{tabular}{llr}
\hline Description & Design Parameter & \multicolumn{1}{c}{ Value } \\
\hline \multirow{3}{*}{ Patch } & Length of Patch $\left(\mathrm{l}_{\mathrm{p}}\right)$ & $44.100 \mathrm{~mm}$ \\
& Width of Patch $\left(\mathrm{w}_{\mathrm{p}}\right)$ & $55.600 \mathrm{~mm}$ \\
Substrate/Ground plane & $0.035 \mathrm{~mm}$ \\
& Patch thickness $(\mathrm{t})$ & $53.720 \mathrm{~mm}$ \\
& Length of Substrate/Ground plane $\left(\mathrm{l}_{\mathrm{s}}=\mathrm{l}_{\mathrm{g}}\right)$ & $65.200 \mathrm{~mm}$ \\
& Width of Substrate/Ground plane $\left(\mathrm{w}_{\mathrm{s}}=\mathrm{w}_{\mathrm{g}}\right)$ & $18.225 \mathrm{~mm}$ \\
Microstrip feed & Inset feed length $\left(\mathrm{l}_{\mathrm{f}}\right)$ & $13.425 \mathrm{~mm}$ \\
& Inset feed length $\left(\mathrm{f}_{\mathrm{l}}\right)$ & $3.644 \mathrm{~mm}$ \\
Substrate & Inset feed Width $\left(\mathrm{w}_{\mathrm{f}}\right)$ & $1.600 \mathrm{~mm}$ \\
Ground plane & Height $(\mathrm{h})$ & $0.035 \mathrm{~mm}$ \\
Patch/Microstrip feed & Thickness $(\mathrm{t})$ & $1.000 \mathrm{~mm}$ \\
\hline
\end{tabular}

\subsection{Model of the proposed inset feed cylindrical surrounding patch antenna}

The proposed CSPA shown in Figure 2 is a rotary version of the RPPA obtained by transformation of the optimized RPPA on a grounded flexible polyimide substrate of curvature radius $(r)$ computed based on the assumption that the perimeter of the cylindrical substrate is equal to the width of the RPPA as:

$$
p=w_{p}=\frac{2 \pi r \theta^{0}}{360^{0}}=r \phi
$$

where $\mathrm{p}$ is the perimeter of the cylinder formed by the substrate and $r$ is the curvature radius while $\theta$ and $\phi$ are angles in degrees and radian formed by the radius of the patch at the center of the cylinder.

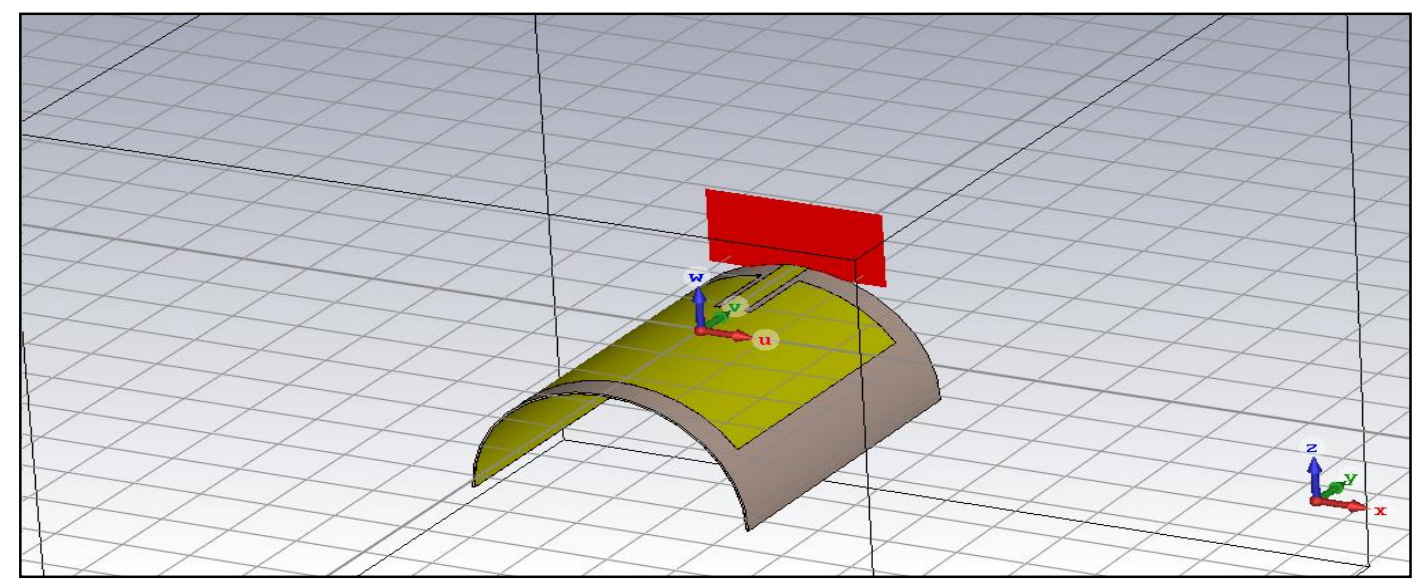

Figure 2. Designed proposed cylindrical surrounding patch antenna 
The RPPA is bent along the patch width (H-plane) since it affects the impedance bandwidth significantly. The other physical dimensional details such as the length of the patch $\left(l_{\mathrm{p}}\right)$ and length of the substrate/ground plane $\left(1_{s} / l_{\mathrm{g}}\right)$ are taken as the height of the cylindrical structure. Since RPPA is intended to be conformally mounted on a cylindrical surface, the choice of a flexible substrate is essential to solve the effect of substrate cracking caused by bending effect and curvature radius. Bending and curvature radius are key determinants of the performance of cylindrical antennas as reported in literatures [17-19]. To reduce the effect of the substrate on the antenna performance, a flexible and almost non-cracking substrate polyimide with a permittivity $\left(\varepsilon_{\mathrm{r}}\right) 3.5$, permeability $\left(\mu_{\mathrm{r}}\right) 1$ and loss tangent $(\tan \delta) 0.0027$ was chosen for the design of the antenna [20]. The cylindrical bending process was achieved by keeping the radius (r) of the cylinder constant at an optimized radius of $10 \mathrm{~mm}$ because decreasing the radius (i.e. increasing the curvature) from higher values to the optimized value increases the bandwidth of the antenna which is a desirable parameter for antenna performance [21, 22].

\section{PARAMETRIC ANALYSIS OF THE PROPOSED CYLINDRICAL SURROUNDING PATCH ANTENNA}

In this work, polyimide material with a thickness of $1.6 \mathrm{~mm}$ has been used as substrate because of its flexibility to conform on cylindrical surface. Various results from the design is presented as follows.

\subsection{Return loss (S-parameter, $\left.S_{11}\right)$}

Figures 3 and 4 shows the return loss $\left(S\right.$-parameter, $\left.S_{11}\right)$ in $\mathrm{dB}$ for the rectangular planar patch antenna and the cylindrical surrounding patch antenna at resonant frequency $\left(\mathrm{f}_{\mathrm{r}}\right) 1.8 \mathrm{GHz}$. The rectangular planar patch antenna achieved a return loss of $-12.784 \mathrm{~dB}$, while the cylindrical surrounding patch antennas with a curvature radius $(r)$ of $10 \mathrm{~mm}$ achieved a return loss of $-35.571 \mathrm{~dB}$.

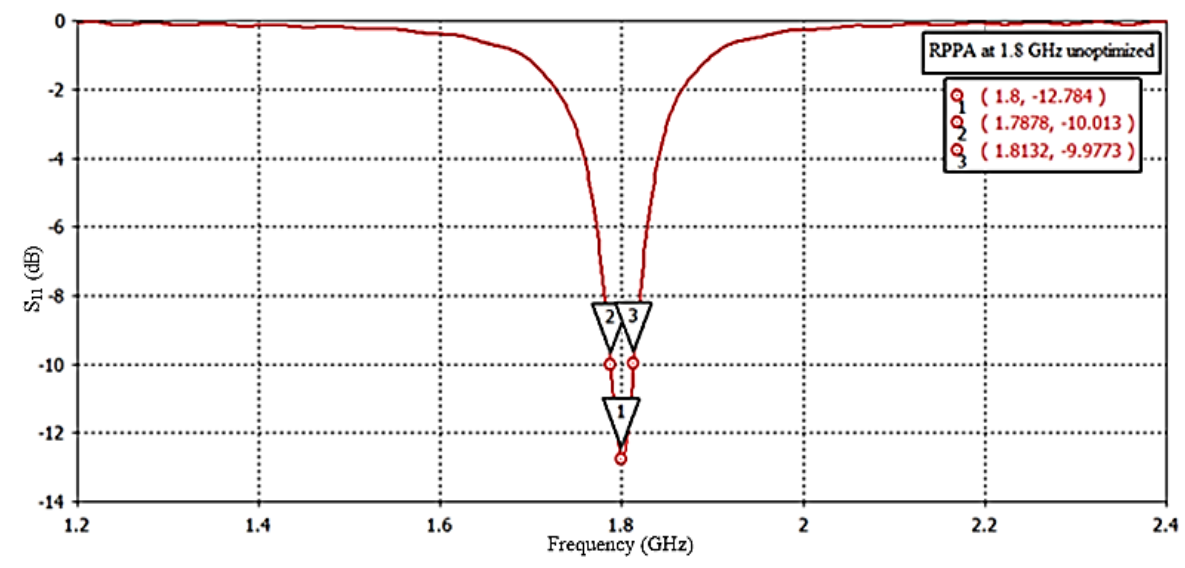

Figure 3. Return loss for rectangular planar patch antenna at $1.8 \mathrm{GHz}$

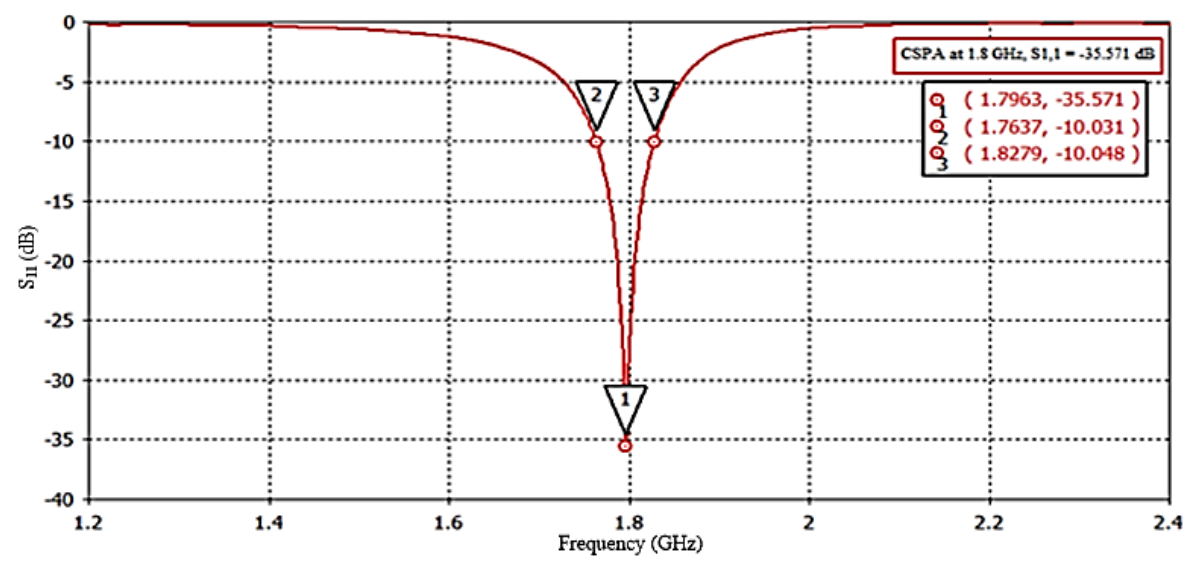

Figure 4. Return loss for cylindrical surrounding patch antenna at $1.8 \mathrm{GHz}$ 


\subsection{Impedance bandwidth}

The impedance bandwidth for the rectangular planar patch antenna and the cylindrical surrounding patch antenna at resonant frequency $\left(f_{r}\right) 1.8 \mathrm{GHz}$ can be obtained from Figure 3 and Figure 4. The rectangular planar patch antenna achieved an impedance bandwidth of $28 \mathrm{MHz}$ at a frequency range of 1.7856-1.8142 $\mathrm{GHz}$ while the cylindrical surrounding patch antennas with a curvature radius (r) of $10 \mathrm{~mm}$ achieved a $-10 \mathrm{~dB}$ impedance bandwidth of $66 \mathrm{MHz}$ at a frequency range of $1.7623-1.8281 \mathrm{GHz}$.

\subsection{Voltage standing wave ratio (VSWR)}

The voltage standing wave ratio (VSWR) shown in Figure 5 and Figure 6 are for the rectangular planar patch antenna and the cylindrical surrounding patch antennas respectively. VSWR indicates the level of matching/mismatch between the signal feed line and the antenna with a typical value of 1:2. The VSWR from the figures are 1.8 and 1.5 respectively. This shows that the two antennas are well matched at the resonant frequency of $1.8 \mathrm{GHz}$.

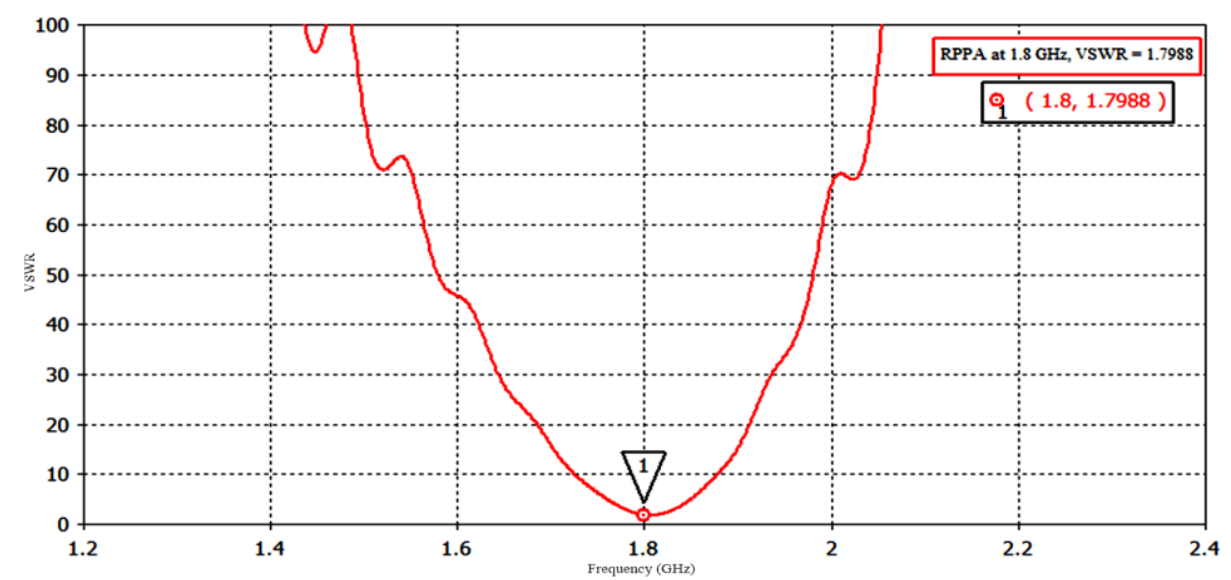

Figure 5. Voltage standing wave ratio for rectangular planar patch antenna at $1.8 \mathrm{GHz}$

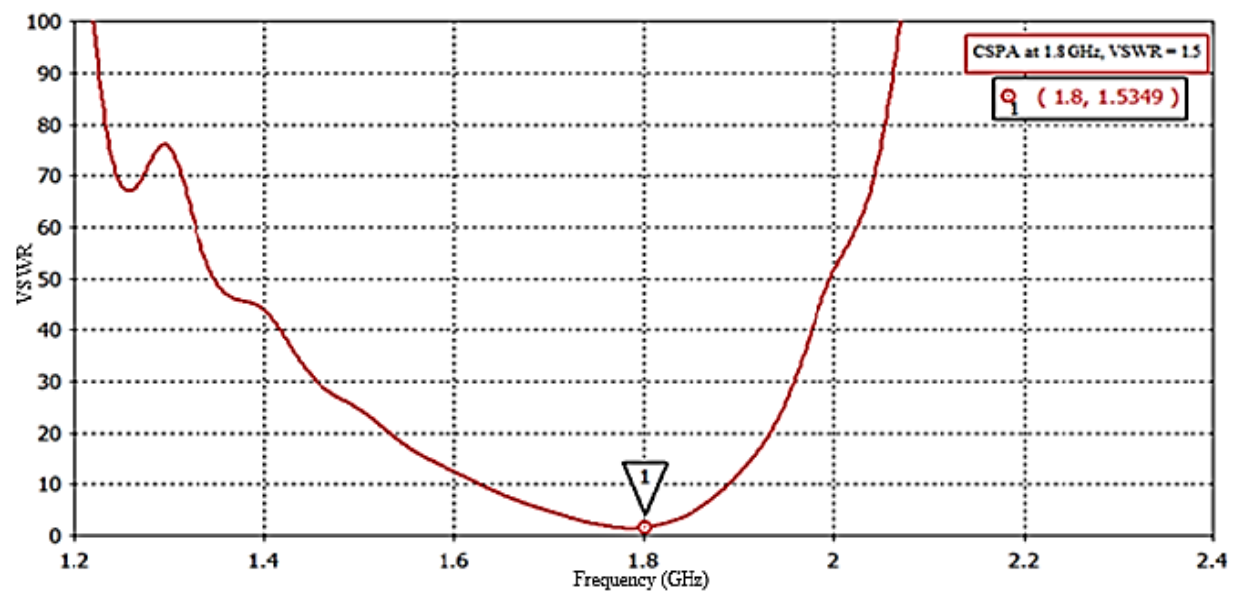

Figure 6. Voltage standing wave ratio for cylindrical surrounding patch antenna at $1.8 \mathrm{GHz}$

\subsection{Farfield radiation pattern}

The farfield radiation pattern is the plot of the farfield properties as a function of spatial co-ordinates specified by elevation angle $(\theta)$ and azimuth $(\phi)$ or can be defined as plot of power radiated per unit solid angle $[11,14,15]$. It could be in polar, Cartesian, 2D or 3D graph. It shows the antenna gain at different points in space as well as the antenna directivity. Figure 7(a) and Figure 7(b) depicts the 3D and polar plot radiation patterns for the rectangular planar patch antenna while Figure 8(a) and Figure 8(b) depicts the 3D and polar plot radiation patterns for the cylindrical surrounding patch antenna. The farfield plot and radiation 
pattern of the cylindrical surrounding patch antenna is different from the rectangular planar patch antenna because its surface is not parallel to the principal axes. The gains of the antennas are $4.81 \mathrm{dBi}$ and $3.47 \mathrm{dBi}$ for the RPPA and the CSPA respectively. From Figure 7(b), the main lobe magnitude, main lobe direction, $3 \mathrm{~dB}$ angular width, and side lobe level for the rectangular planar patch antenna are $4.78 \mathrm{dBi}, 0.0 \mathrm{deg}$., $98.9 \mathrm{deg}$., and $-8.6 \mathrm{~dB}$ at $1.8 \mathrm{GHz}$ respectively. From Figure $8(\mathrm{~b})$, the main lobe magnitude, main lobe direction, and $3 \mathrm{~dB}$ angular widths for the cylindrical surrounding patch antenna are $3.34 \mathrm{dBi}, 0.0 \mathrm{deg}$., and $174.8 \mathrm{deg}$. at $1.8 \mathrm{GHz}$ respectively.

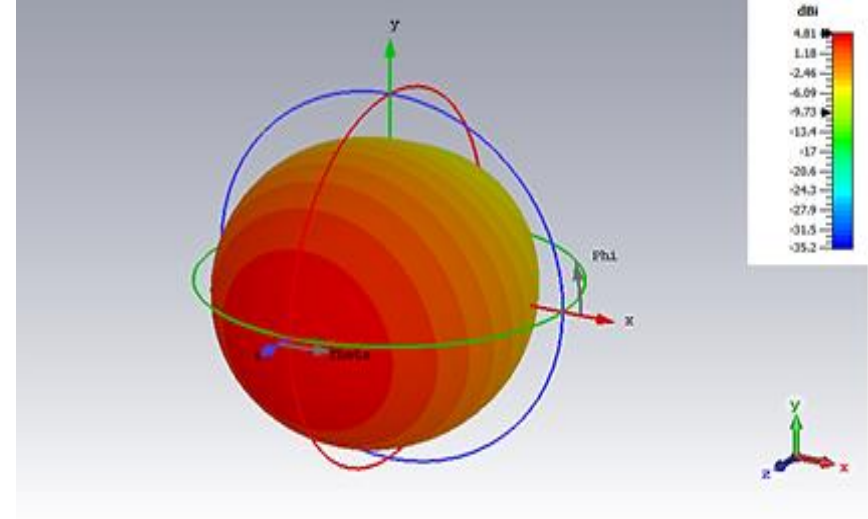

(a)

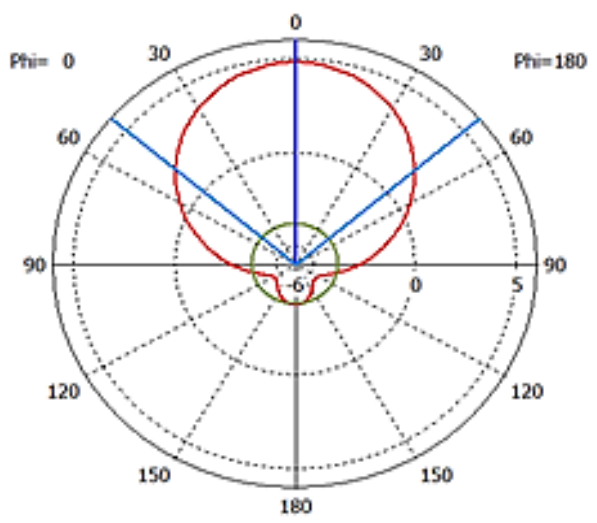

(b)

Figure 7. (a) Farfield 3D-radiation pattern for rectangular planar patch antenna and

(b) Farfield plot of radiation pattern for rectangular planar patch antenna

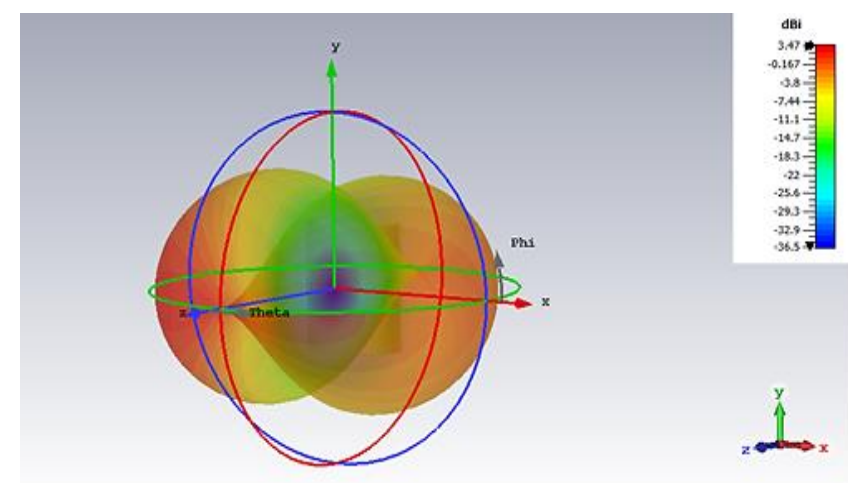

(a)

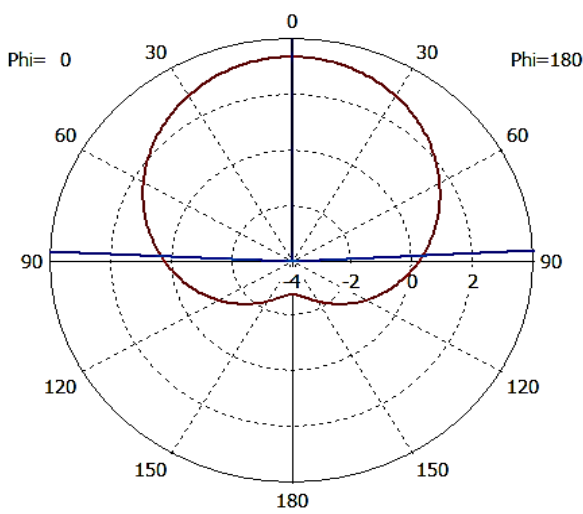

(b)

Figure 8. (a) Farfield 3D-radiation pattern for cylindrical surrounding patch antenna and (b) Farfield plot of radiation pattern for cylindrical surrounding patch antenna

\section{COMPARISON OF THE PROPOSED CYLINDRICAL SURROUNDING PATCH ANTENNA WITH EXISTING DESIGNS}

The selection of a feeding technique is a critical issue for patch antennas because it affects the patch size, return loss, VSWR, BW, and Smith chart $[17,23]$. The authors chose inset feed technique because it simple to model, easy to fabricate, and easy to match in terms of impedance [23]. The performance of the proposed cylindrical surrounding patch antenna has been compared with existing designs in other to support its importance as a candidate antenna for curved surface applications as reported in literature. The comparison is shown in Table 2. 
Table 2. Comparison of proposed antenna with existing designs

\begin{tabular}{|c|c|c|c|c|c|c|}
\hline Reference & $\begin{array}{l}\text { Substrate } \\
\text { Type }\end{array}$ & Feed Type & $\begin{array}{l}\text { Antenna size } \\
\left(\mathrm{mm}^{3}\right)\end{array}$ & $\begin{array}{l}\text { Resonant } \\
\text { frequency }(\mathrm{GHz})\end{array}$ & $\begin{array}{l}\text { Return } \\
\text { loss }(\mathrm{dB})\end{array}$ & Gain (dBi) \\
\hline [24] & Polyamide & Microstrip/Inset & $50 \times 40 \times 0.8$ & $1.8 / 13.3$ & -16 to -43 & 5.53 \\
\hline [25] & $\begin{array}{l}\text { Roger's RT } \\
\text { Duriod } 5880\end{array}$ & Coaxial & $200 \times 200 \times 6$ & $1.8 / 2.4 / 3.5 / 5.8$ & -17 t0 -30 & $2.6 / 2.3 / 3 / 2$ \\
\hline [26] & Plexiglass & Microstrip & $56 \times 44 \times 0.8$ & $1.575 / 2.45 / 3.5 / 5.2$ & -22 to -28 & $3.55 / 3.93 / 5.02 / 4.86$ \\
\hline [27] & $\begin{array}{l}\text { Roger's RT } \\
\text { Duriod } 5880\end{array}$ & NA & $51 \times 35 \times 1.57$ & $1.2 / 1.5 / 2.4 / 3.3 / 5.8$ & NA & $1.07 / 1.75 / 1.88 / 1.52 / 5.48$ \\
\hline [30] & FR4 & Inset Microstrip & $58 \times 40 \times 1.6$ & $2.4 / 5 / 5.87$ & -12 to -27 & $5.2 / 4.8 / 5$ \\
\hline $\begin{array}{l}\text { Proposed } \\
\text { antenna }\end{array}$ & Polyimide & Inset Microstrip & $44 \times 55.6 \times 0.035$ & 1.8 & -35.571 & 3.47 \\
\hline
\end{tabular}

\section{CONCLUSIONS AND FUTURE ASPECTS}

In this paper, we have proposed a cylindrical surrounding patch antenna for application in $1.8 \mathrm{GHz}$ application for mobile communication where antennas have to be integrated on curved surfaces. Antenna performance parameters such as return loss, impedance bandwidth, VSWR, and radiation pattern for the rectangular planar patch antenna and the cylindrical surrounding patch antenna has been investigated with reference to its planar counterpart. It has been observed that using a cylindrical grounding structure could increase frequency bandwidth, better beamwidth, and good radiation characteristics of the patch. Also, it has been observed that the physical size of an antenna is usually inversely proportional to its resonant frequency. The proposed CSPA compared to existing designs as shown in Table 2 is suitable for vehicular application. The antenna performance parameter such as gain, bandwidth, greater beam width and better coverage (angular width) etc. can be improved by use of array antennas. This will further enhance ominidirectionality and portability.

\section{REFERENCES}

[1] L. M. Bhowmik, et al., "Design and analysis of conformal Ku-band microstrip patch antenna arrays," IEEE International Symposium, pp. 815-820, 2013.

[2] K. L. Wong, "Compact and broadband microstrip antennas," John Wiley \& Sons, 2002.

[3] Erhiega N. Umayah and Viranjay M. Srivastava, "Radiation pattern of novel cylindrical surrounding patch antenna for $2.4 \mathrm{GHz}$ applications," Int. J. of Electrical and Electronic Engineering \& Telecommunications, vol. 8, no. 4, pp. 213-220, 2019.

[4] N. T. Markad, et al., "Design of cavity model microstrip patch antenna," Computer Engineering and Intelligent Systems, vol. 6. no. 4, pp. 1-13, 2015.

[5] A. Elrashidi, et al., "Input impedance, VSWR and return loss of a conformal microstrip printed antenna for TM01 mode using two different substrates," International Journal of Networks and Communications, vol. 2, no. 2, pp. 13-14, 2011.

[6] S. Lakrit, et al., "A new small high-gain wideband rectangular patch antenna for X and Ku bands applications," Journal of Taibah University for Science, vol. 12, no. 2, pp. 202-207, 2018.

[7] R. Sahoo and D. Vakula, "A cylindrical conformal antenna for GPS application," 8th International Conference on Computing, Communication and Networking Technologies, pp. 1-4, 2017.

[8] Elfatimi A., Bri S., and Saadi A., "Comparison between techniques feeding for simple rectangular, circular and triangular patch antenna at $2.45 \mathrm{GHz}$," 4th IEEE International Conference on Optimization and Applications, pp. 1-5, 2018.

[9] A. Kumar, N. Gupta, and P. C. Gautam, "Gain and bandwidth enhancement techniques in microstrip patch antennas-a review," International Journal of Computer Applications, vol. 148, no. 7, pp. 9-14, 2016.

[10] Erhiega N. Umayah and Viranjay M. Srivastava, "Comparative view of return loss, VSWR, gain, and efficiency of cylindrical surrounding patch antenna with frequency shift," Int. J. of Electrical and Electronic Engineering \& Telecommunications, vol. 8, no. 6, pp. 352-357, 2019.

[11] Ayodele S. Oluwole and Viranjay M. Srivastava, "Features and futures of smart antennas for wireless communications: A technical review," Journal of Engineering Science and Technology Review, vol. 11, no. 4, pp. 8-24, 2018.

[12] H. K. Varshney, M. Kumar, A. K. Jaiswal, et al., "A survey on different feeding techniques of rectangular microstrip patch antenna," International Journal of Current Engineering and Technology, vol. 4, no. 3, pp. 418-423, 2014.

[13] S. D. Gupta, M. C. Srivastava, and A. Singh, "Design and performance analysis of cylindrical microstrip antenna and array using conformal mapping technique," Communication Engineering Applications, vol. 2, pp. 166-180, 2011.

[14] C. A. Balanis, "Antenna Theory Analysis and Design," 5th Ed. John Wiley and Sons, 2005.

[15] K. L. Wong, "Design of nonplanar microstrip antennas and transmission lines," John Wiley and Sons, New York, USA, 2004.

[16] N. Kalambe, D. Thakur, and S. Paul, "Review of microstrip patch antenna using UWB for wireless communication devices," International Journal of Computer Science and Mobile Computing, vol. 4, no. 1, pp. 128-133, 2015.

[17] K. Elleithy, H. Bajwa, and A. Elrashidi, "Conformal microstrip printed antenna," American Society for Engineering Education, 2011. 
[18] T. Mitha and M. Pour, "Conformal wideband microstrip patch antennas on cylindrical platforms," Progress In Electromagnetics Research Letters, vol. 80, pp. 1-6, 2018.

[19] David Ferreira, et al., Examining the effect of bending on their performance," IEEE Antennas and Propagation Magazine, vol. 59, no. 3, pp. 54-59, 2017.

[20] L. D. Jang, W. K. Li, H. Y. Chi, et al., "Advance polyimide materials: Syntheses, physical properties and applications," Progress in Polymer Science, vol. 37, no. 7, pp. 907-974, 2012.

[21] P. Li, K. L. Lau, and K. M. Luk, "A study of the wide-band L-probe fed planar patch antenna mounted on a cylindrical or conical surface," IEEE transactions on Antennas and Propagation, vol. 53, no. 10, pp. 3385-3389. 2005.

[22] F. Xu, L. Sun, K. Zhang, et al., "Electromagnetic performance and impact damage of the microstrip antennas integrated in cylindrical three dimensional woven composite structures," Polymer Composites, vol. 39, no. 9, pp. 3259-3267, 2018.

[23] L. C. Paul, et al., "The effect of changing substrate material and thickness on the performance of inset feed microstrip patch antenna," American Journal of Networks and Communications, vol. 4, no. 3, pp. 54-58, 2015.

[24] S. Mohandoss, S. K. Palaniswamy, R. R. Thipparaju, et al., "On the bending and time domain analysis of compact wideband monopole antennas," International Journal of Electronic Communication, vol. 101, pp. 168-181, 2019.

[25] W. Lee, et al., Omnidirectional low-profile multiband antenna for vehicular telecommunication," Progress in Electromagnetic Research Letters, vol. 53, pp. 53-59, 2015.

[26] Y. F. Cao, S. W. Cheung, and T. I. Yul, "A multiband slot antenna for GPS/WiMAX/WLAN systems," IEEE Transaction on Antennas and Propagation, vol. 63, no. 3, pp. 952-958, 2015.

[27] T. R. Rao, "Design and performance analysis of a penta-band spiral antenna for vehicular communications," Wireless Personal Communications, vol. 96, no. 3, pp. 3421-3434, 2017.

[28] K. Fujita, K. Yoshitomi, K. Yoshida, and H. Kanaya, "A circularly polarized planar antenna on flexible substrate for ultra-wideband high-band applications," International Journal of Electronic Communication, vol. 69, no. 9, pp. 1381-1386, 2015.

[29] S. Mulla and S. S. Deshpande, "Compact multiband fed with wideband coupled line impedance transformer for improvement of impedance matching," Microwave optical Technology Letters, vol. 59, no. 9, pp. 2341-2348, 2017.

[30] P. M. Paul, K. Kandasamy, and M. S. Sharawi, "A tri-band slot antenna loaded with split ring resonators," Microwave and Optical Technology Letters, vol. 59, no. 10, pp. 2638-2643, 2017. 